\title{
¿PUEDEN LOS TRIBUNALES ESPAÑOLES PRONUNCIARSE SOBRE LOS DERECHOS DE CUSTODIA DE UNA MENOR RESIDENTE EN ECUADOR? COMENTARIO DE LA SENTENCIA DE LA AUDIENCIA PROVINCIAL DE BARCELONA 468/2020, DE 23 DE JULIO DE 2020
}

\author{
CAN THE SPANISH COURTS RULE ON THE CUSTODY RIGHTS \\ OF A MINOR RESIDENT IN ECUADOR? COMMENTARY \\ ON THE JUDGMENT OF THE PROVINCIAL COURT OF \\ BARCELONA 468/2020 OF 23 JULY 2020
}

\author{
Antonia Durán Ayago \\ Profesora Titular de Derecho Internacional Privado \\ Universidad de Salamanca
}

Recibido: 12.11.2020 / Aceptado: 04.12.2020

DOI: https://doi.org/10.20318/cdt.2021.5993

\begin{abstract}
Resumen: Una madre de nacionalidad ecuatoriana y residente en España solicita ante los órganos jurisdiccionales españoles la custodia sobre su hija que reside en Ecuador, cuidada por su abuela materna. El juzgado de instancia considera que no tiene competencia para conocer de este procedimiento, para lo que de forma incomprensible alega el artículo 10 del Convenio de La Haya de 1996 en un procedimiento que no tiene carácter matrimonial, dado que los progenitores no estaban casados. La apelación ratifica la falta de competencia judicial internacional sobre la base del artículo 5 del citado Convenio.

Palabras clave: responsabilidad parental, derechos de custodia, competencia judicial internacional, residencia habitual del menor.

Abstract: A mother of ecuadorian nationality and resident in Spain applies to the Spanish courts for custody of her daughter who resides in Ecuador, cared for by her maternal grandmother. The court considers that it does not have competence to hear this procedure, for which Article 10 of the 1996 Hague Convention argues in an incomprehensible way in a procedure that is not matrimonial in nature, since the parents were not married. The appeal confirms the lack of international judicial competence on the basis of Article 5 of the Convention.
\end{abstract}

Keywords: parental responsibility, custody rights, international jurisdiction, habitual residence of the minor.

Sumario: I. Con carácter previo II. En concreto, los hechos III. Respuesta jurídica a) Incorrecto enfoque: el artículo $10 \mathrm{CH} 1996$ no es aplicable b) Sobre la determinación de la residencia habitual de la hija c) Sobre la posibilidad de aplicación del artículo 9 CH 1996 d) Sobre la inadmisión, que no la desestimación, de la demanda IV. En conclusión. 


\section{Con carácter previo}

1. No son pocos los casos que han llegado a los tribunales españoles en los que se les insta a que se pronuncien sobre los aspectos relacionados con los derechos de custodia y de visita, también de alimentos, solicitados por progenitores que tienen su residencia en nuestro país, pero cuyos hijos han quedado al cuidado de algún familiar en sus países de origen ${ }^{1}$, mayoritariamente latinoamericanos ${ }^{2}$. En estos casos, urge concretar, primero, qué texto normativo nos proporcionará la respuesta que buscamos y, en segundo lugar, si conforme a este texto dispondrán los órganos jurisdiccionales españoles de competencia judicial internacional para pronunciarse al respecto.

2. En nuestro ordenamiento jurídico, el actual sistema de protección internacional de menores o de responsabilidad parental, en terminología adaptada a los textos internacionales de los que nuestro país forma parte ${ }^{3}$, es complejo, debido a que concurren normas de diferente procedencia que se interrelacionan entre sí y sobre las que no siempre es sencillo concretar su ámbito de aplicación ${ }^{4}$. En la actualidad, son cuatro los textos normativos que pueden concurrir a la hora de determinar el régimen normativo de los derechos de custodia y de visita sobre los hijos comunes de una pareja en crisis. Junto con el Reglamento (CE) 2201/2003 del Consejo de 27 noviembre 2003 relativo a la competencia, el reconocimiento y la ejecución de resoluciones judiciales en materia matrimonial y de responsabilidad parental, por el que se deroga el Reglamento (CE) $n^{\circ} 1347 / 2000$ [en adelante, Reglamento (CE) 2201/2003]', sustituido ya por el Reglamento (UE) 2019/1111 del Consejo de 25 de junio de 2019 relativo a la competencia, el reconocimiento y la ejecución de resoluciones en materia matrimonial y de responsabilidad parental, y sobre la sustracción internacional de menores ${ }^{6}$, pero que no comenzará a aplicarse hasta el 1 de agosto de 2022, se encuentran el Convenio de La Haya de 19 de octubre de 1996, sobre la competencia, la ley aplicable, el reconocimiento, la ejecución y la cooperación en materia de responsabilidad parental y medidas de protección de los niños (en adelante, $\mathrm{CH}$ 1996) ${ }^{7}$, la Ley 54/2007, de 28 de diciembre, de adopción internacional (en adelante, LAI) ${ }^{8}$, también la Ley Orgánica del Poder Judicial (en adelante, LOPJ).

Con carácter general, si el hijo es menor de edad conforme a su ley personal (art. $9.1 \mathrm{Cc}$ ) y reside en un Estado miembro del Reglamento (CE) 2201/2003, se aplicará dicho Reglamento. Si reside en un tercer Estado no parte del CH 1996, si se cumplen condiciones del artículo 12 Reglamento (CE) 2201/2003 (forum divortii), el Reglamento podría aplicarse. Si el hijo no reside en un Estado miembro del Reglamento, se aplica el CH 1996, siempre que el hijo sea menor de 18 años y resida en un Estado miembro del Convenio. Para el resto de casos, se aplicaría la LOPJ. La LAI, en los supuestos de responsabilidad parental, únicamente se aplica en lo relativo al reconocimiento de decisiones ${ }^{9}$.

\footnotetext{
${ }^{1}$ Portodos,SAPValencia2marzo2020[ECLI:ES:APV:2020:833];AAPBarcelona16deabril2018[ECLI:ES:APB:2018:1367A]; AAP Barcelona 17 mayo 2017 [ECLI:ES:APB:2017:3796A]; SAP Barcelona 10 abril 2015 [ECLI:ES:APB:2015:3667] y SAP Madrid 18 junio 2013 [ECLI:ES:APM:2013:11880].

${ }^{2}$ C. Solé (dra.), "Los vínculos económicos y familiares transnacionales: Los inmigrantes ecuatorianos y peruanos en España”, accesible en https://www.fbbva.es/wp-content/uploads/2017/05/dat/DE_2007_vinculos_economicos_y_familiares.pdf, consultado el 9 de noviembre de 2020; ConSEJo ECONÓMICO Y SoCIAL DE EsPAÑA, "Informe 02|2019 La inmigración en España; efectos y oportunidades", accesible en http:/www.ces.es/documents/10180/5209150/Inf0219.pdf, consultado el 9 de noviembre de 2020; C. GonzÁLez BeILfuss, "La nulidad, separación y divorcio en el Derecho internacional privado español: cuestiones de competencia judicial internacional y ley aplicable", Cursos de Derecho internacional y relaciones internacionales de Vitoria-Gasteiz, nº 1, 2011, pp. 135-194, esp. p. 159.

${ }^{3}$ A Durán Ayago, "Responsabilidad parental, relaciones paterno-filiales y protección de menores: ¿tres denominaciones para tres realidades diferentes?", en C. Esplugues Mota / M. GuZmán Zapater (dirs.), Persona y familia en el nuevo modelo español de Derecho Internacional Privado, Tirant lo Blanch, 2017, pp. 353-363.

${ }^{4}$ F. Garau Sobrino, "Notas sobre la colisión de fuentes de Derecho Internacional privado español sobre responsabilidad parental y protección del niño", Cuadernos de Derecho Transnacional (marzo 2011), vol. 3, nº 1, pp. 282-289.

${ }^{5}$ DOUE L 338 de 23 diciembre 2003.

${ }^{6}$ DOUE L 178 de 2 julio 2019.

${ }^{7}$ En vigor para España desde el 1 de enero de 2011. BOE núm. 291, de 2 de diciembre de 2010.

${ }^{8}$ BOE núm. 312, de 29 de diciembre de 2007.

${ }^{9}$ A. Durán Ayago, "Ejercicio de los derechos de custodia y de visita en un mundo globalizado: riesgos y disfunciones. Especial referencia al forum divortii en el contexto europeo", en A. Cebrián Salvat / I. Lorente Martínez, Protección de menores en Derecho Internacional Privado, Comares, 2019, pp. 91-102.
} 
3. La sentencia que vamos a analizar, dictada por la Audiencia Provincial de Barcelona el 23 de julio de $2020^{10}$, resuelve un recurso de apelación, desestimándolo, contra la sentencia de instancia en un procedimiento de guarda y custodia iniciado por la madre, de nacionalidad ecuatoriana y residente en España, en el que solicitaba el derecho de custodia sobre su hija, también ecuatoriana y residente en Ecuador, bajo el cuidado de su abuela materna. Las dos instancias coinciden en que los órganos jurisdiccionales españoles no poseen competencia judicial internacional para pronunciarse sobre este asunto, justificando la de instancia esta falta de competencia, de forma errónea, en un precepto inaplicable, en el contexto de los hechos, como es el forum divortii del artículo 10 CH 1996.

\section{En concreto, los hechos}

4. De los datos que se aportan en el texto de la sentencia se extraen las siguientes circunstancias, relevantes para decidir el caso. En primera instancia, se había considerado que el tribunal español no tenía competencia para conocer de los hechos, que, como apuntábamos, versan sobre la solicitud de los derechos de custodia de una madre de nacionalidad ecuatoriana y residente en España, sobre su hija, también ecuatoriana y residente en Ecuador, especificándose que se encuentra bajo el cuidado de su abuela materna. No se precisa dónde reside el padre, aunque se indica que impide la salida de la niña de Ecuador, por lo que es muy probable que en este país resida. Los progenitores de la menor no están casados. Este hecho es relevante, puesto que el precepto que utiliza la resolución de instancia para declararse incompetente (según el juzgado, para desestimar la demanda), no cuestionado por la apelación, es un artículo, el $10 \mathrm{CH}$ 1996, pensado para la concentración jurisdiccional del pleito en los casos de separación judicial y divorcio (forum divortii), por lo que únicamente podría aplicarse en los procedimientos matrimoniales.

5. A pesar de citar este artículo, la argumentación que desarrollan gira en torno a la falta de proximidad del órgano jurisdiccional español y no en concreto sobre las condiciones que deberían darse para aplicar el citado precepto. Y así, se hace hincapié en que la menor reside en Ecuador, cuidada por un familiar y con sus gastos administrados por un tercero, gastos no probados y distintos de los que pudiera tener en España, y con unas visitas difíciles de fijar en atención a la distancia. Además, el juzgado sostiene que resolver sobre las medidas solicitadas por la madre respondería a una realidad fáctica distinta y, por tanto, no redundaría en beneficio de la menor. En atención a ello, y amparándose en que no dispone de prueba alguna sobre la situación real de la menor, acuerda la desestimación íntegra de la demanda (sic).

6. Frente a la referida resolución recurre la demandante, alegando que la sentencia de instancia deja a la menor en una absoluta indefensión al privarle de vivir con su madre, añadiendo que ella está legitimada en cualquier caso para obtener la guarda y custodia de su hija y la patria potestad sobre la niña al amparo de la legislación ecuatoriana, y ello, aunque ésta se encuentre viviendo con su abuela al no poder salir de Ecuador por impedirlo su padre.

Hay que precisar que, en principio, jurídicamente no tendría relevancia en el proceso esta alusión por parte de la madre a que el padre no deja salir a la menor de Ecuador, a no ser que esta circunstancia fuera tenida en cuenta para poder aplicar el artículo $9 \mathrm{CH}$ 1996, como más adelante veremos. Hay que tener en cuenta que no ha habido ningún cambio de residencia de la hija, al menos acreditado en el proceso, por lo que no cabe intuir una retención ilícita, más teniendo en cuenta que ha quedado al cuidado de la abuela materna. Tampoco consta una resolución previa de los órganos jurisdiccionales ecuatorianos en que se haya otorgado el derecho de custodia a la madre, lo que podría justificar ese traslado a España en atención a un procedimiento de reubicación familiar ${ }^{11}$. De los hechos que figuran en el

\footnotetext{
${ }^{10}$ ECLI:ES:APB:2020:6159.

${ }^{11}$ Vid. Nota preliminar sobre la reubicación familiar internacional elaborada por la Conferencia de La Haya de Derecho Internacional Privado, enero 2012, accesible en https://assets.hcch.net/upload/wop/abduct2012pd11s.pdf, consultado el 11 de noviembre de 2020 .
} 
proceso nada de esto ha sucedido, por lo que se manifiestan las dificultades de conseguir desde España una resolución que le favorezca.

7. Por su parte, la Audiencia Provincial no entra a valorar los hechos, puesto que parte de que los únicos tribunales con competencia para conocer del caso son los de Ecuador, sobre la base del principio de proximidad.

\section{Respuesta jurídica}

\section{a) Incorrecto enfoque: el artículo 10 CH 1996 no es aplicable}

8. Tanto el juzgado de instancia como la Audiencia Provincial de Barcelona determinan correctamente el texto jurídico de referencia para resolver la cuestión de la competencia judicial internacional. En virtud del artículo 61 del Reglamento 2201/2003, el CH 1996 prevalece siempre que el niño resida en un Estado que sea parte únicamente del Convenio, y Ecuador lo es desde el 1 de septiembre de $2003^{12}$. El CH 1996 se aplica porque se solicita un pronunciamiento sobre los derechos de custodia, materia comprendida en el ámbito de aplicación material del Convenio [arts. 1.2 y 3.a)], sobre una menor de 18 años (art. 2) y con residencia habitual en un Estado parte del Convenio (Ecuador) (art. 5).

9. Es preciso reseñar que el Convenio se aplica a todas las medidas relacionadas con la protección de los menores, con independencia de que, en el caso de estar relacionadas con el ejercicio de la patria potestad, estos sean o no hijos matrimoniales, ya que se regulan en él los derechos y obligaciones que pertenecen al padre y a la madre en virtud de la ley, para cuidar a sus hijos y asegurar su desarrollo, ya se trate de la guarda, de la educación, de la fijación de residencia, o de la vigilancia de la persona del niño, particularmente en sus relaciones ${ }^{13}$.

En el caso, al no tratarse de un matrimonio, sorprende que la justificación normativa en que se sustente su falta de competencia judicial internacional sea el artículo $10^{14}$, que en este caso no sería siquiera aplicable, puesto que lo que establece este artículo es un forum divortii ${ }^{15}$, esto es, la posibilidad de concentración jurisdiccional del pleito relativo a los derechos de custodia y de visita sobre los hijos comunes en el tribunal que esté conociendo de la separación judicial o el divorcio de los progenitores. Lo curioso es que, aun aludiendo a este artículo como base de la no competencia, no se justifica por qué conforme a este artículo no la tienen, es decir, no detallan los presupuestos de aplicación ni por qué en este caso no se dan.

\footnotetext{
${ }^{12}$ Para comprobar el estado de ratificaciones del Convenio, puede accederse a https://www.hcch.net/es/instruments/conventions/status-table/?cid $=70$.

${ }^{13}$ Vid. Informe explicativo del Convenio elaborado por P. Lagarde disponible en https://assets.hcch.net/upload/expl34s.pdf (consultado el 12 de noviembre de 2020) en su párrafo 14.

${ }^{14} \mathrm{El}$ tenor del artículo $10 \mathrm{CH} 1996$ es el siguiente: “1. Sin perjuicio de los artículos 5 a 9, las autoridades de un Estado contratante, en el ejercicio de su competencia para conocer de una demanda de divorcio o separación de cuerpos de los padres de un niño con residencia habitual en otro Estado contratante o en anulación de su matrimonio, pueden adoptar, si la ley de su Estado lo permite, medidas de protección de la persona o de los bienes del niño, si: a) uno de los padres reside habitualmente en dicho Estado en el momento de iniciarse el procedimiento y uno de ellos tiene la responsabilidad parental respecto al niño, y b) la competencia de estas autoridades para adoptar tales medidas ha sido aceptada por los padres, asi como por cualquier otra persona que tenga la responsabilidad parental respecto al niño, si esta competencia responde al interés superior del niño. 2. La competencia prevista en el apartado primero para adoptar medidas de protección del niño cesa cuando la decisión aceptando o desestimando la demanda de divorcio, separación de cuerpos o anulación del matrimonio sea firme o el procedimiento finaliza por otro motivo.".

${ }^{15}$ De forma errónea, el auto de la Audiencia Provincial de Barcelona 16 de abril 2018 [ECLI:ES:APB:2018:1367A] que indica que en el CH 1996 no se regula un forum divortii, similar al regulado en el artículo 12 del Reglamento 2201/2003.
} 


\section{b) Sobre la determinación de la residencia habitual de la hija}

10. La Audiencia Provincial, por su parte, orienta la falta de competencia judicial internacional fijándose únicamente en el artículo 5 CH 1996, en virtud del cual los tribunales competentes serían los de Ecuador, puesto que es en este Estado donde reside la menor. Según la Audiencia, "la atribución de la competencia a los tribunales correspondientes al lugar de residencia del menor responde al fin último de proteger el superior interés de este. El criterio competencial de la residencia habitual del menor es adoptado en las normas internacionales citadas no solo por la eficacia de la acción de los tribunales en sus propios territorios, sino también en función del interés del menor. De ahí la prevalencia de la proximidad del órgano jurisdiccional de la residencia del menor en el momento de interposición de la demanda, al ser el que está en mejor condición para conocer su situación y sus necesidades". Y esta es toda la argumentación que da al respecto.

11. No profundiza en los detalles de esa residencia habitual, lo que no hubiera estado de más, en la medida en que este concepto no es definido por el Convenio, y se constituye como una cuestión fáctica que deberá resolverse a la luz de las circunstancias de cada caso. De interés es el razonamiento que sobre la residencia habitual ofrece la sentencia de la Audiencia Provincial de Barcelona de 10 de abril de 2015, en un caso muy parecido al que analizamos, puesto que también se rechazó la competencia judicial internacional de los tribunales españoles en un supuesto de custodia solicitado por la madre, residente en España y nacional de Ecuador, sobre sus tres hijos menores de edad residentes en Ecuador, en este caso porque no se aportaban pruebas sobre la posibilidad real de que las hijas pudieran ser trasladadas a España, puesto que la madre no contaba con medios de vida suficientes para mantenerlas, pero daba a entender que si así hubiera sido, ello incluso hubiera podido determinar que la residencia de sus hijas hubiera estado en España. Al respecto, en su argumentación hace alusión a que en algunos casos la intencionalidad de las personas que ostentan la potestad parental adquiere especial relevancia en los supuestos de cambio de residencia, es decir, cuando hay pruebas claras de la intención de los progenitores de comenzar una nueva vida en otro Estado, de manera que podría sostenerse que si la intención de la madre era la de trasladar la residencia de las menores a España de forma inminente, habiendo realizado gestiones en este sentido, el lugar de residencia de las menores estaría en España, aun cuando mantuviesen temporalmente su residencia en Ecuador. Aun así, la Audiencia en la misma sentencia reconocía que existe otro enfoque que se centra en la realidad fáctica de la vida del niño para determinar el concepto de residencia. Esta realidad fáctica incluye elementos tales como el centro escolar del menor, la interacción social, las relaciones familiares del menor en dicho Estado, pudiendo afirmarse que el concepto de residencia habitual se corresponde con el lugar en el que el menor tenga una cierta integración en su entorno social y familiar ${ }^{16}$. A estos efectos también son circunstancias que hay que tomar en consideración la duración, la regularidad, las condiciones y las razones de permanencia en el territorio del estado y los motivos del traslado a dicho Estado, la nacionalidad de los menores, etcétera ${ }^{17}$.

12. Estos interesantes razonamientos que ofrece la Audiencia Provincial de Barcelona en 2015 están completamente ausentes en la sentencia que comentamos. No hubiera estado de más una mínima argumentación en torno a ello, puesto que en el caso se trasluce la necesidad para la madre de contar con una sentencia que le permita trasladar la residencia de su hija con ella a España. Si se tiene en cuenta que la niña está siendo cuidada por la abuela materna, parece conveniente y hasta necesario que la Audiencia se hubiera esforzado en decidir y tratar con perspectiva de género el caso ${ }^{18}$.

${ }^{16}$ I. Otaegui Aizpurua, "La errónea determinación de la competencia judicial internacional cuando los hijos residen en Estados miembros diferentes: Sentencia de la AP de Lugo no 44/2018, de 11 de abril de 2018", Cuadernos de Derecho Transnacional (Marzo 2019), Vol. 11, № 1, pp. 870-876; I. ReIG FABADO, "La construcción del concepto autónomo de residencia habitual del menor en los supuestos de sustracción internacional de menores", Cuadernos de Derecho Transnacional (Marzo 2019), Vol. 11, No 1, pp. 877-888.

${ }^{17}$ En tal sentido se manifiestan la sentencia del TJUE de 2 de abril de 2009, C-523/07 y también la sentencia de 22 de diciembre de 2010, C-497/10.

${ }^{18} \mathrm{Vid}$. por todos, I. VIVAS TeSón, "La transformación del derecho de familia desde una perspectiva de género", en I. VÁz- 


\section{c) Sobre la posibilidad de aplicación del artículo 9 CH 1996}

13. Ambas instancias se muestran tan convencidas de que los tribunales competentes son los de Ecuador que obvian entrar a justificar, por ejemplo, por qué no consideran la aplicación del artículo $9^{19}$, en el que se regulan los casos en los que procedería un forum conveniens ${ }^{20}$, esto es, los casos en los que sería posible reclamar para sí la competencia por considerarse en mejor situación que las autoridades que con carácter general tienen competencia ${ }^{21}$.

Ciertamente, en términos estrictos no se dan los supuestos en que España podría reclamar para sí la competencia, dado que no concurría ninguno de los establecidos en el artículo 8.2 CH 1996, a saber, ser el Estado del que el niño es nacional; en que estén situados sus bienes; en el que se esté conociendo de una demanda de divorcio o separación de cuerpos de sus padres o de anulación de su matrimonio o con el que el niño mantenga algún vínculo estrecho. Es este último concepto, el mantener un vínculo estrecho con España el que, por tratarse de un concepto jurídico indeterminado, quizás hubiera interesado concretar. A priori, este vínculo con España sería indirecto, a través de la madre, que es la que reside en España y la que insta aquí el procedimiento. En puridad, sería el único resquicio para que los tribunales españoles hubieran demandado para sí la competencia. Pero no hubiera sido descabellado recurrir a su aplicación. Al menos, debería haberse justificado por qué no procedía recurrir a él. Las circunstancias que se conocen entiendo que justificarían haberlo hecho. Debería haberse valorado, por ejemplo, la imposibilidad real para la madre de iniciar un procedimiento de custodia en Ecuador por estar residiendo en España; el hecho de que el efectivo cuidado de su hija lo está ejerciendo su madre, con lo que la figura paterna de alguna manera quedaría desdibujada o la intención de la madre de traer con ella a su hija a España y no poder hacerlo porque el padre se opone a ello.

14. El artículo 9 CH 1996 señala claramente en su último apartado que la autoridad de origen de la solicitud sólo puede ejercer su competencia en lugar de la autoridad del Estado contratante de la residencia habitual del niño si esta autoridad ha aceptado la petición. En la sentencia de la Audiencia Provincial de Barcelona de 17 de mayo de 2017, se indica "[t]eniendo en consideración las circunstancias concurrentes en el presente supuesto en el que consta que la madre otorgó una autorización de custodia a favor de la abuela materna, con la que convive la menor en la República Dominicana, en enero de 2014, la Sala estima que deberá ser la demandante la que plantee su demanda ante los Tribunales de la República Dominicana a los que se considera en principio en mejor situación para resolver sobre lo que constituye objeto de la presente demanda". Como vemos, en esta resolución existe un análisis de si procede o no que a través del artículo 9 los tribunales españoles tengan competencia, a diferencia de lo que ocurre en la sentencia que comentamos que carece de toda argumentación al respecto.

En todo caso, no es esta la opción por la que optan ni el juzgado de instancia ni la Audiencia Provincial que ni siquiera aluden al artículo 9, por considerar que son las autoridades ecuatorianas las

QUEZ BERMÚDEZ (coord.), Investigaciones multidisciplinares en género: II Congreso Universitario Nacional "Investigación y Género", Sevilla, 17 y 18 de junio de 2010, pp. 1207-1231.

${ }^{19}$ Artículo 9: "1. Si las autoridades de los Estados contratantes mencionados en el artículo 8, apartado 2, consideran que están en mejor situación para apreciar, en un caso particular, el interés superior del niño, pueden ya sea - solicitar a la autoridad competente del Estado contratante de la residencia habitual del niño, directamente o con la cooperación de la Autoridad Central de este Estado, que les permita ejercer su competencia para adoptar las medidas de protección que estimen necesarias, o ya sea - invitar a las partes a presentar dicha petición ante las autoridades del Estado contratante de la residencia habitual del niño. 2. Las autoridades interesadas pueden proceder a un intercambio de opiniones. 3. La autoridad de origen de la solicitud sólo puede ejercer su competencia en lugar de la autoridad del Estado contratante de la residencia habitual del niño si esta autoridad ha aceptado la petición.".

${ }^{20}$ Vid. B. SÁnChez López, "Responsabilidad parental y la aplicación del forum non conveniens de carácter reglado del artículo 15 del Reglamento (CE) No 2201/2003: la STJUE de 27 de octubre de 2016", Cuadernos de Derecho Transnacional (Marzo 2018), Vol. 10, No 1, pp. 639-656; M. A. Rodríguez VÁzQUEz, "La remisión y la transferencia de competencia en materia de responsabilidad parental en el Reglamento (UE) 2019/1111", Cuadernos de Derecho Transnacional (Octubre 2020), Vol. 12, No 2, pp. 706-723.

${ }^{21}$ Así, por ejemplo, lo hicieron el AAP Barcelona, de 17 de mayo de 2017 [ECLI:ES:APB:2017:3796A] y SAP Barcelona, de 10 de abril de 2015 [ECLI:ES:APB:2015:3667]. 
que, en virtud de la residencia de la menor, están en mejor situación para decidir sobre los derechos de custodia de la niña. Y con ello optan por la vía menos complicada, pero probablemente no la más indicada en el caso.

\section{d) Sobre la inadmisión, que no la desestimación, de la demanda}

15. Otra cuestión que sorprende de lo que indica la sentencia de apelación es que el juzgado de primera instancia desestima integramente la demanda al apreciar falta de competencia judicial internacional para pronunciarse sobre las citadas medidas. La cuestión es que no se puede desestimar lo que en puridad no se ha podido conocer. Si se trata de una cuestión de falta de competencia judicial internacional, lo que habría que determinar es si de oficio se ha controlado o se ha hecho a instancia del padre, pero, en cualquier caso, desestimar no es lo mismo que inadmitir. Tal y como dispone el artículo 404.2 a) LEC, procede la inadmisión de la demanda cuando se estime falta de jurisdicción o competencia del Tribunal.

\section{En conclusión}

16. Como hemos señalado, hay varias disfunciones presentes en la resolución de este caso, tanto en primera instancia como en apelación. En lo que respecta a la resolución de instancia, aludir al artículo 10 CH 1996 para determinar la falta de competencia de los órganos jurisdiccionales españoles no es correcto, porque en ningún caso este precepto sería aplicable dado que no estamos ante un procedimiento matrimonial, ya que los progenitores no estaban casados. No alude, por el contrario, al resto de preceptos que podrían justificar la competencia judicial internacional de los órganos jurisdiccionales españoles, en particular el artículo 9, en el que se regula un forum conveniens, lo que hubiera sido adecuado para justificar su falta de competencia. Las circunstancias que alega la demandante (estar su hija bajo el cuidado de su madre; padre que impide que la niña salga de Ecuador...) lo aconsejaban, pero lejos de eso, se dicta resolución por la que se desestima íntegramente la demanda, lo que tampoco es correcto, puesto que se trataría de un caso de inadmisión por falta de competencia judicial internacional.

17. La Audiencia Provincial se limita a confirmar lo decidido por la primera instancia, centrándose en el artículo 5 CH 1996, como si no hubiera otros foros contemplados en el Convenio. La perspectiva que eligen es errónea, puesto que no analizan por qué los órganos jurisdiccionales españoles no estarían en disposición de conocer de la demanda, sino que se centran en que los competentes son los de Ecuador porque allí reside la hija, indicándole a la madre que es en este país donde debe instar lo que considere conveniente.

18. Considero que ambas instancias se tendrían que haber esforzado en justificar por qué conforme al Convenio no tienen competencia, no dar por sentado que hay un foro de competencia judicial internacional único sustentado en la residencia habitual de la menor. Este es el criterio general, pero no el único. El resto de foros también pueden otorgar competencia en virtud de diversos factores a las autoridades de otro Estado parte. En este sentido, quizás sería conveniente recordar el funcionamiento del artículo 9, claramente explicado por el relator del Convenio, Paul Lagarde, en los párrafos 57 a 60 del Informe ${ }^{22}$. Ciertamente, su aplicación requiere esfuerzo y una comunicación fluida entre las autoridades españolas y las ecuatorianas, y entiendo que las circunstancias alegadas por la madre hubieran justificado ese esfuerzo. No es lo mismo llegar al resultado de la falta de competencia judicial internacional habiendo transitado primero el camino de analizar todas las posibilidades de disponer de competencia, que haber optado de entrada por determinar que sólo las autoridades de Ecuador tienen competencia. Aunque se hubiera llegado al mismo resultado, la calidad de los pronunciamientos judiciales hubiera sido muy diferente.

\footnotetext{
${ }^{22}$ Accesible en https://assets.hcch.net/upload/expl34s.pdf, consultado el 12 de noviembre de 2020.
} 